\title{
STATORS USE INFLUENCE ON THE PERFORMANCE OF A SAVONIUS WIND ROTOR USING COMPUTATIONAL FLUID DYNAMICS
}

\begin{abstract}
J. V. Akwa, ABSTRACT
and A. P. Petry,

Universidade Federal do Rio Grande do Sul

Departamento de Engenharia Mecânica

Escola de Engenharia

Bairro Centro

Cep 90050-170, Porto Alegre, Rio Grande do

Sul, Brasil

joao.akwa@ufrgs.br adrianep@mecanica.ufrgs.br

This paper aims at verifying the influence of using five kinds of stators in the averaged moment and power coefficients of a Savonius wind rotor using computational fluid dynamics (CFD). The analyzed stators have cylindrical shape with two and three openings, one and four deflector blades and walls shaped like a wings. The equations of continuity, Reynolds Averaged NavierStokes - RANS and the Eddy Viscosity Model k- $\omega$ SST, in its Low-Reynolds approaches, with hybrid near wall treatment; are numerically solved using the commercial software Star- $\mathrm{CCM}^{+}$, based on Finite Volume Method, resulting in the fields of pressure and velocity of the flow and the forces acting on the rotor buckets. The moment and power coefficients are achieved through integration of forces coming from the effects of pressure and viscosity of the wind on the buckets device. The influence of the stators use in the moment and power coefficients is checked by changing the geometry of the device for each simulations series, keeping the Reynolds number based on rotor diameter equal to 433,500 . The obtained values for averaged moment and power coefficients indicate that for each type of stator used, there was maximum performance for a given tip speed ratio of rotor. Improvement in performance over the operation without stator was obtained only to the operations using stator with four deflector blades and to the stator with cylindrical shape with three openings. The improvement percentage in performance obtained for the best condition (use of four deflector blades at tip speed ratio equal to 1 ) is $12 \%$ compared to the performance of the rotor operating without stator.
\end{abstract}

Keywords: Savonius wind turbine, stators, CFD

\section{NOMENCLATURE}

a spacing between the rotor buckets, $m$

a face area vector, $\mathrm{m}^{2}$

A area, $\mathrm{m}^{2}$

$\mathrm{A}_{\mathrm{r}} \quad$ rotor area, $\mathrm{m} 2$

c chord, $m$

$\mathrm{C}_{\mathrm{T}}, \mathrm{C}_{\mathrm{P}}$ moment and power coefficients, Eq. (29)

d distance vector, $\mathrm{m}$

$d_{\mathrm{pe}} \quad$ diameter of the end plate, $m$

$\mathrm{d}_{\mathrm{r}} \quad$ rotor diameter, $\mathrm{m}$

D cross-derivative term

e thickness of the buckets, $\mathrm{mm}$

$\mathrm{F} \quad$ blending function

$\boldsymbol{F}_{f}^{\text {pressure }}, \boldsymbol{F}_{f}^{\text {shear }}$ pressure and shear force vectors, N

$\mathrm{g}$ turbulence model coefficient

$\mathrm{G}$ production

I turbulence intensity, \%

$\mathrm{k}$ turbulent kinetic energy, $\mathrm{J} / \mathrm{kg}$

$k_{f} \quad$ position of the face

$\mathrm{L}$ turbulent length scale, $\mathrm{m}$

$\mathrm{p}$ pressure, $\mathrm{Pa}$

$\mathrm{P}$ power, $\mathrm{W}$

$\overline{\mathrm{p}}$ average pressure, $\mathrm{Pa}$

$\mathrm{r}$ rotor radius, $\mathrm{m}$

Re Reynolds number, $\rho u x / \mu$ s overlap, $\mathrm{m}$

S mean strain rate tensor

$\mathrm{S}_{\mathrm{k}}, \mathrm{S}_{\omega_{\mathrm{t}}}$ user-specified source terms

$\mathrm{t}$ time, $\mathrm{s}$

$\mathrm{T}$ rotor moment, $\mathrm{Nm}$

$\mathrm{u}^{*} \quad$ reference velocity, $\mathrm{m} / \mathrm{s}$

$\mathrm{u}^{+} \quad$ non-dimensionalized velocity, $\mathrm{u} / \mathrm{u}^{*}$

$\overline{\mathrm{u}}_{\mathrm{i}} \quad$ average velocity of air flow, $\mathrm{m} / \mathrm{s}$

$\mathrm{u}_{\mathrm{i}}^{\prime} \quad$ velocity fluctuation, $\mathrm{m} / \mathrm{s}$

v velocity vector, $\mathrm{m} / \mathrm{s}$

$\mathrm{V} \quad$ cell volume

$\mathrm{V}_{\mathrm{o}} \quad$ undisturbed velocity, $\mathrm{m} / \mathrm{s}$

$\mathrm{X}, \mathrm{Y}, \mathrm{Z}$ cartesian coordinates, $\mathrm{m}$

$\mathrm{y}$ transverse distance, $\mathrm{m}$

$\mathrm{y}+\quad$ dimensionless wall distance, Eq. (21)

\section{Greek symbols}

$\gamma_{\text {eff }}$ effective intermittency

$\theta \quad$ buckets angular position, $\mathrm{rad}$

$\lambda$ tip speed ratio, $\omega r / \mathrm{V}_{\mathrm{o}}$

$\mu \quad$ dynamic viscosity, Pa.s

$\mu_{\mathrm{t}} \quad$ turbulent viscosity, Pa.s

$v \quad$ kinematic viscosity, $\mathrm{m}^{2} / \mathrm{s}$

$\rho \quad$ specific mass, $\mathrm{kg} / \mathrm{m}^{3}$ 
$\sigma \quad$ inverse turbulent Schmidt number

$\phi, \beta^{*}, \alpha^{*}, \beta, \gamma, \kappa, \mathrm{a}_{1}$, arg, turbulence model coefficients

$\tau \quad$ stress tensor

$\omega$ angular velocity, $\mathrm{rad} / \mathrm{s}$

$\omega_{\mathrm{t}} \quad$ specific dissipation rate, $\mathrm{s}^{-1}$

\section{Subscripts}

0 free stream or initial values

1, 2 turbulence coefficients of Set 1 and Set 2

f face

$\mathrm{k} \quad$ turbulent kinetic energy

$r$ rotor

ref reference

t turbulent

$\omega_{\mathrm{t}} \quad$ specific dissipation rate

\section{INTRODUCTION}

The use of unconventional devices like the Savonius wind turbines can be a solution for low cost and reduced environmental impacts for decentralized power generation. The wind rotor developed and patented in 1929 by Sigurd J. Savonius from Helsingfors at Finland, has, among other advantages: simple construction; high torque at startup and in full operation; accepting wind from any direction for the operation; low noise and low angular velocity in operation, which reduces wear on moving parts; in addition to various rotor configuration options, as for example, the use of multiple stages and different shapes of buckets (Savonius, 1930; Vance, 1973; Fernando and Modi, 1989).

A Savonius wind turbine, however, cannot be regarded as a wind machine with performance higher and nor lower than performance of the other wind devices from power generation. Savonius turbines should only be understood as different mechanisms for the utilization of wind energy, and technological alternatives to conventional wind devices (Vance, 1973; Eldridge, 1980). The turbine created by Savonius works mainly due to the resulting drag force on their buckets (Savonius, 1930). According to Akwa (2010), lift forces are also responsible for part of the power provided by the device.

As it was reported by Akwa (2010), the performance of a Savonius rotor is affected by flow parameters and geometry of the turbine. For a given flow configuration, different arrangements of Savonius turbine provide different performances in converting wind energy into useful energy. According to Akwa et al. (2009) and Akwa (2010), an increase in the performance of a Savonius rotor can happen with using stators external to the rotor. The stators lead an increase in the mass flow through the projected area of the rotor, increasing the power of the device to the same undisturbed wind speed. Small changes in geometry of the stators can promote large variations in the averaged moment and power coefficients. For this reason, this paper aims at verifying the influence of using five kinds of stators in the averaged moment and power coefficients of a Savonius wind rotor using computational fluid dynamics (CFD). The analyzed stators have cylindrical shape with two and three openings, one and four deflector blades and walls shaped like a wings. The results were obtained by applying the Finite Volume Method to solve the conservation equations of the turbulent air flow on the turbine, which allows the calculation of the performance coefficients of the rotor.

\section{METHODOLOGY}

\section{Description of Phenomenon}

In this research work, the performance of a two bucket Savonius turbine with semicircular profiles buckets, like the one shown in Fig. 1, was analyzed. A two-dimensional modeling for the geometry of the turbine (Fig. 1-b) in operation is performed, whereas in such a device, with high aspect ratio as can be seen in Figure 1-a, the changes in the profile of the flow caused by the effects of the turbine tips can be considered small. The operation of the Savonius rotor is simulated with variations in the geometry of the stator. In Figure 1-c, two-dimensional representations of the rotors tested with different stators are displayed.

The cylindrical shape stators with two and three openings are among the analyzed stators. These stators were inspired in the study of Sabzevari (1978), which achieved improved in rotor performance with the use of such stators. According Sabzevari (1978), the boundary layer separation on the outer surface of the cylindrical stators creates a region with low pressure downstream of the diffuser. This increases the mass flow through the rotor, improving the performance of the wind device.

Another used stator is a stator with walls shaped like a wings, inspired in the study of Hansen (2008), which obtained performance improvement in the operation of horizontal axis wind turbines with this type of stator. As Hansen (2008), the flow through the stator generates a lift force, which creates a ring vortex, which by the Biot-Savart law will induce a velocity to increase the mass flow through the rotor, improving the power of the turbine.

Static deflector blades can be used in an attempt to decrease the resistant moment caused by drag force of wind on the returning bucket as described by Akwa (2010). For this reason, one and four static deflector blades were used in conjunct with rotor in computational simulations to verify a possible performance gain. Large number of deflectors are needed for applications where there is wind coming from several directions. The same was thought to the deflector openings of the cylindrical stators. 
In Figure 1-b, the diameter of the end plate, $d_{p e}$, has a value of $1.1 \mathrm{~m}$, while the value of the rotor diameter, $d_{r}$, is $1 \mathrm{~m}$. The thickness of the buckets, e, is $4 \mathrm{~mm}$ and the spacing between the rotor buckets, a, is null. $\theta$ indicates the buckets angular position of the rotor that have a constant angular velocity, $\omega$, in wind with undisturbed velocity at a value equal to $\mathrm{V}_{\mathrm{o}}$.

The relationship between the overlap, $s$, and the chord, c, of the rotor buckets $(\mathrm{s} / \mathrm{c})$ is kept constant at value of 0.15 for all simulations. The parameters of the rotor and flow are always adjusted to each analysis keeping the Reynolds number, based on rotor diameter and undisturbed flow velocity, equal to 433,500 .

The rotor is considered to be immersed in a turbulent air flow and operating at certain constant rotation rate. This phenomenon is reproduced by simulating the rotor operation in a domain that containing air under atmospheric conditions. The conservation equations of the turbulent air flow on the turbine are numerically solved for obtain the velocity and pressure fields in the calculation domain and the forces acting on all the surfaces of turbine. The moment and power coefficients are achieved through integration of forces coming from the effects of pressure and viscosity of the wind on the rotor. The calculation domain is spatially discretized by cells of quad and triangular format to solve the equations using the Finite Volume Method (Patankar, 1980).

The dimensions of the calculation domain, given in multiples of the turbine diameters, and the boundary conditions adopted for the solution of conservation equations are shown in Fig. 2. The size of the calculation domain was chosen so that the boundaries just stay away from the turbine and thereby not affecting the performance of wind energy device, as is commented by Akwa (2010). Inside calculation domain, a circular region with sliding mesh is bounded containing the contours of the rotor. This circular region has a diameter equivalent to 1.10 rotor diameters and center at 6 turbine (rotor with stator) diameters of the inlet and the sides of the calculation domain.
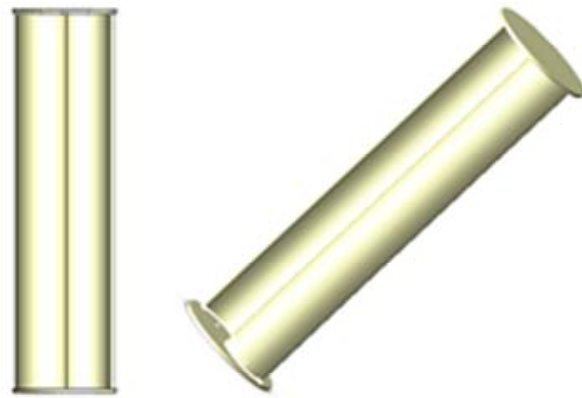

(a)

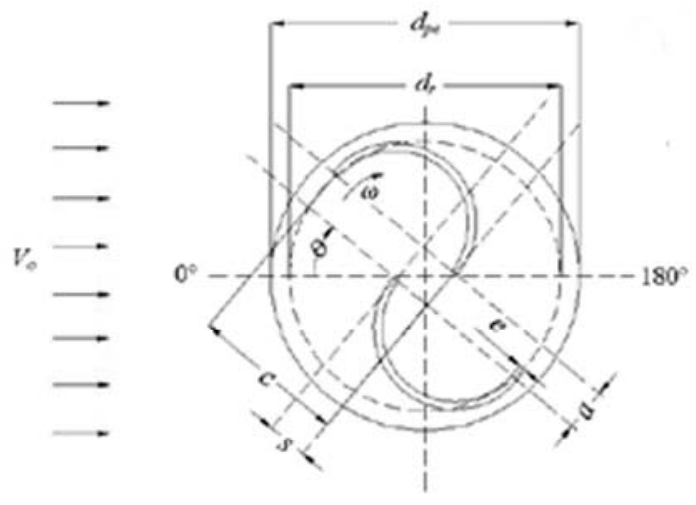

(b)

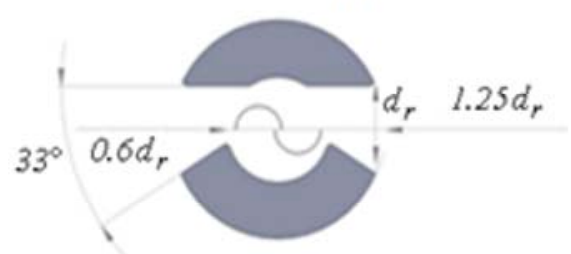

Cylindrical with two openings

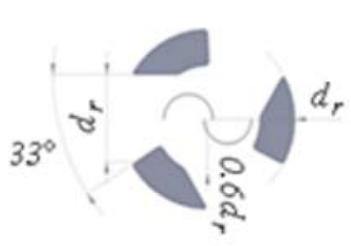

Cylindrical with three openings

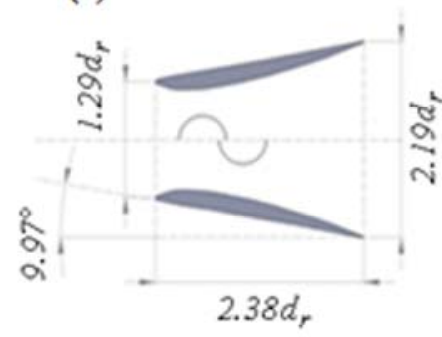

Walls shaped like a wings

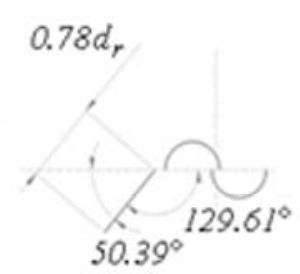

One deflector blade

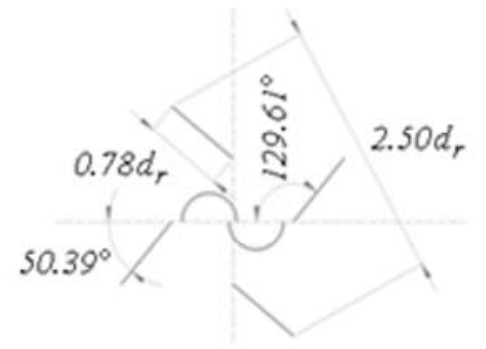

Four deflector blades

(c)

Figure 1. Savonius turbine: (a) 3D rotor; (b) 2D rotor; (c) rotor with stator. 
At the inlet of the calculation domain, a velocity value for the air flow is prescribed, while at the outlet of the domain the pressure is considered equivalent to atmospheric pressure. The sides of the calculation domain are considered as symmetry planes. On the surface of the turbine, is considered the no-slip condition. As boundary conditions for calculating the effects of turbulence are used characteristic length and intensity of turbulence. As initial condition, it is considered homogeneous fields of pressure and velocity in the flow. The rotation of the wind device is set to each simulation by specifying the rotation rate of the region of sliding mesh.

In Figure 2, a rotor without stator is represented for better understanding. In the computational simulations with turbine equipped with stators, the external limits of the calculation domain are given in multiples of the maximum diameter of the stator considered.

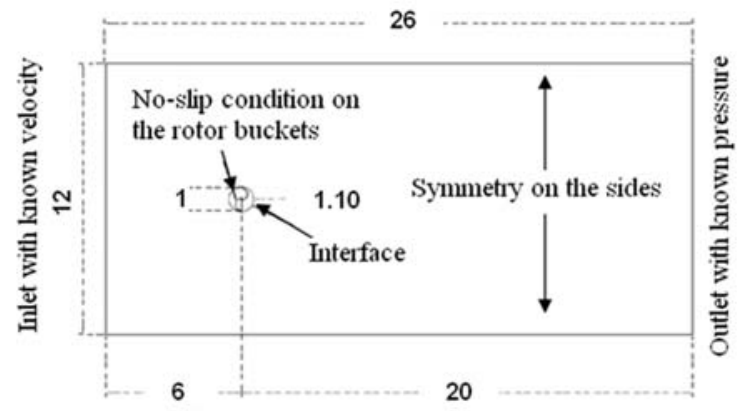

Figure 2. Calculation domain and boundary conditions.

\section{Details of the Domain Discretization}

The equations of continuity, Reynolds Averaged Navier-Stokes - RANS and the Eddy Viscosity Model k- $\omega$ SST, in its Low-Reynolds approaches, with hybrid near wall treatment; are numerically solved using the commercial software Star-CCM+, based on Finite Volume Method, resulting in the fields of pressure and velocity of the flow and the forces acting on the turbine surfaces. Applying this method, the calculation domain under study is divided into a finite number of elementary control volumes. The finite volume discretization transforms the differential equations governing the flow in a linear system of algebraic equations that is solved iteratively. This is due to the substitution of infinitesimal differences by finite differences in the differential equations. The calculated values of the variables are assigned to the centroids of each of the volumes. Thus the solution is discrete, depending on the number of elementary volumes present in the calculation domain (Maliska, 1995).

For purposes of domain discretization, a mesh with quadrilateral and triangular volumes was done. The mesh consists of up to three regions: the first is fixed and mapped with quad volumes (Fig. 3-a), the second is fixed and unstructured with triangular volumes in the vicinity of stators (Fig. 3-b), and the third is sliding and unstructured with triangular volumes close to the rotor. The sliding mesh is located in the region circumscribed by the interface (Fig. 3-c). The sliding domain is constructed with a non-structured mesh with triangular volumes, which ensures a better adaptation to the curved geometry of the rotor; while the external fixed domain consists of a mapped mesh, ensuring a better organization and reducing the effects of numerical diffusion (Maliska, 1995; Akwa, 2010). The mesh fixed and unstructured with triangular volumes in the vicinity of stators is also used due a better adaptation to the curved geometry of the stators which the use this kind of mesh provides. Near the buckets and stator surfaces are used layers of the finest quad volumes in order to improve the assessment of the boundary layer (Fig. 3c).

\section{Mass Balance and Momentum Equations}

In this research work, the results were obtained by applying the Finite Volume Method to solve the conservation equations of the turbulent air flow on the Savonius turbine, which allows the calculation of the performance coefficients of the rotor. Among these conservation equations, there is a mass balance equation.

$$
\frac{\partial}{\partial \mathrm{x}_{\mathrm{i}}}\left(\bar{u}_{i}+u_{i}^{\prime}\right)=0
$$

The Equation (1) with indicial notation represents the mass balance, where $\bar{u}_{i}$ is the average velocity of air flow and $\mathrm{u}_{\mathrm{i}}^{\prime}$ is the velocity fluctuation due to the effects of turbulence, and $x$ represents the direction of flow.

$$
\begin{aligned}
& \frac{\partial \bar{u}_{i}}{\partial t}+\bar{u}_{j} \frac{\partial \bar{u}_{i}}{\partial x_{j}} \\
& =-\frac{1}{\rho} \frac{\partial \bar{p}}{\partial x_{i}}+\frac{\mu}{\rho} \frac{\partial^{2} \bar{u}_{i}}{\partial x_{j} \partial x_{j}}-\frac{\partial}{\partial x_{j}} \overline{u_{i}^{\prime} u_{j}^{\prime}} \\
& \frac{d}{d t} \int_{V} \rho k d V+\int_{A} \rho k\left(v-v_{g}\right) \cdot d \boldsymbol{a} \\
& =\int_{\mathrm{A}}\left(\mu+\sigma_{\mathrm{k}} \mu_{t}\right) \nabla k \cdot d \boldsymbol{a}+ \\
& \int_{V}\left(\gamma_{e f f} G_{k}-\gamma^{\prime} \rho \beta^{*} f_{\beta}\left(\omega_{t} k-\omega_{t 0} k_{0}\right)+S_{k}\right) d V
\end{aligned}
$$

The momentum equation must be solved along with the mass balance equation. The Equation (2) represents the momentum equation, where $t$ is the 
time, $\overline{\mathrm{p}}$ is average pressure, $\rho$ is the density and $\mu$ is the dynamic viscosity of atmospheric air.

$$
\begin{aligned}
& \frac{\mathrm{d}}{\mathrm{dt}} \int_{\mathrm{V}} \rho \omega_{\mathrm{t}} \mathrm{dV}+\int_{\mathrm{A}} \rho \omega_{\mathrm{t}}\left(\boldsymbol{v}-\boldsymbol{v}_{\boldsymbol{g}}\right) \cdot \mathrm{d} \boldsymbol{a} \\
& =\int_{\mathrm{A}}\left(\mu+\sigma_{\omega_{\mathrm{t}}} \mu_{\mathrm{t}}\right) \nabla \omega_{\mathrm{t}} \cdot \mathrm{d} \boldsymbol{a}+ \\
& \int_{\mathrm{V}}\left(\mathrm{G}_{\omega_{\mathrm{t}}}-\rho \beta \mathrm{f}_{\beta}\left(\omega_{\mathrm{t}}^{2}-\omega_{\mathrm{t} 0}^{2}\right)+\mathrm{D}_{\omega_{\mathrm{t}}}+\mathrm{S}_{\omega_{\mathrm{t}}}\right) \mathrm{dV}
\end{aligned}
$$

\section{Turbulence Model}

From the Equation (2), arises the term $\rho \overline{u_{i}^{\prime} u_{j}^{\prime}}$ that is the stresses tensor of Reynolds introducing six additional unknowns. To solve the closure problem caused by the emergence of new unknowns, the turbulence model k- $\omega$ SST, in its Low-Reynolds approaches, is used because it's the one that best fits the studied phenomenon (Wilcox, 1998; Menter e Kuntz, 2002; Star-CCM ${ }^{+}$, 2008; Akwa, 2010). The model solves the equations of turbulent kinetic energy k, calculated by Eq. (3), and specific dissipation rate $\omega_{t}$, calculated by Eq. (4).

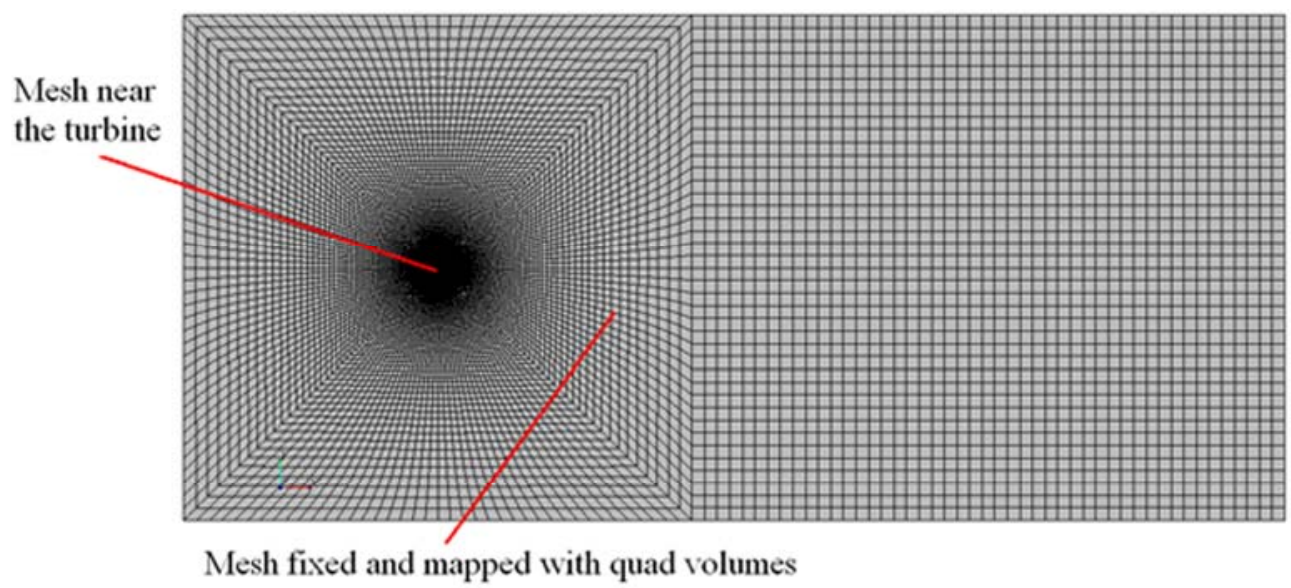

(a)

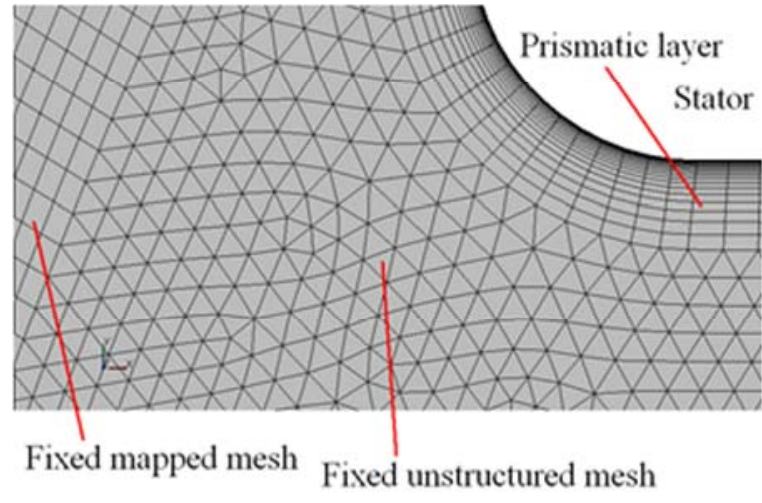

(b)

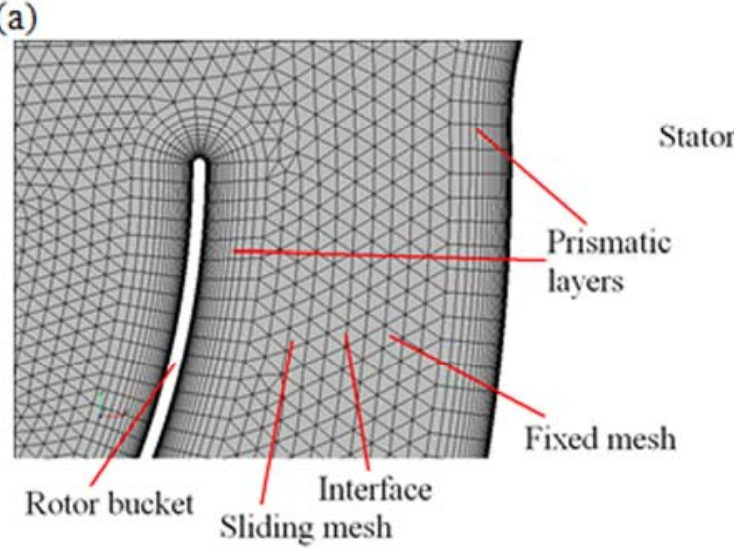

(c)

Figure 3. Used mesh: (a) overview of the discretizated domain; (b) region near the external surface of the stator; (c) region near the interface.

$$
\gamma^{\prime}=\min \left[\max \left(\gamma_{\text {eff }}, 0.1\right), 1\right]
$$

In the equations of turbulence model, $\mathrm{V}$ is the cell volume, $\mathrm{A}$ is area, $\mathrm{a}$ is a face area vector, $\mathrm{v}$ is velocity of the flow, $\mathrm{v}_{\mathrm{g}}$ is the velocity of the grid, $\sigma_{\mathrm{k}}$ and $\sigma_{\omega_{\mathrm{t}}}$ are inverse turbulent Schmidt numbers, $\mu_{\mathrm{t}}$ represents turbulent viscosity, $\mathrm{S}_{\mathrm{k}}$ and $\mathrm{S}_{\omega_{\mathrm{t}}}$ are the user-specified source terms, $\mathrm{k}_{0}$ and $\omega_{\mathrm{t} 0}$ are the ambient turbulence values in source terms that counteract turbulence decay, and $\gamma_{\text {eff }}$ is the effective intermittency provided by the Gamma ReTheta Transition model that is unity if this model is not activated. $\gamma^{\prime}$ is calculated by Eq. (5).

$$
\begin{aligned}
& \mathrm{G}_{\omega_{\mathrm{t}}}=\rho \gamma\left[\left(\mathrm{S}^{2}-\frac{2}{3}(\nabla \cdot \boldsymbol{v})^{2}\right)-\frac{2}{3} \omega_{\mathrm{t}} \nabla \cdot \boldsymbol{v}\right] \\
& \mathrm{G}_{\mathrm{k}}=\mu_{\mathrm{t}} \mathrm{S}^{2}-\frac{2}{3} \rho \mathrm{k} \nabla \cdot v-\frac{2}{3} \mu_{\mathrm{t}}(\nabla \cdot v)^{2}
\end{aligned}
$$




$$
\begin{aligned}
& \boldsymbol{S}=\frac{1}{2}\left(\nabla \boldsymbol{v}+\nabla \boldsymbol{v}^{\mathrm{T}}\right) \\
& \mathrm{T}_{\mathrm{k} \omega_{\mathrm{t}}}=\min \left(\frac{1}{\max \left(\omega_{\mathrm{t}} / \alpha^{*},\left(\mathrm{SF}_{2}\right) / \mathrm{a}_{1}\right)}, \frac{0.6}{\sqrt{3 \mathrm{~S}}}\right) \\
& \mathrm{D}_{\omega_{\mathrm{t}}}=2\left(1-\mathrm{F}_{1}\right) \rho \sigma_{\omega_{\mathrm{t}} 2} \frac{1}{\omega_{\mathrm{t}}} \nabla \mathrm{k} \cdot \nabla \omega_{\mathrm{t}}
\end{aligned}
$$

$\mathrm{G}_{\omega_{\mathrm{t}}}$ is the production of $\omega_{\mathrm{t}}$ is evaluated by the Eq. (6), where $\gamma$ is a blended coefficient of the model and $\mathrm{S}$ is the modulus of the mean strain rate tensor $(S=|\mathbf{S}|)$. Similarly, the production of $k, G_{k}$, is defined by Eq. (7). $\mathbf{S}$ is evaluated by Eq. (8). $\mathrm{T}_{\mathrm{k} \omega_{\mathrm{t}}}$ is a time scale that is computed using the Eq. (9). The term $\mathrm{D}_{\omega_{\mathrm{t}}}$ in the Equation (4) is a cross-derivative term, defined by the Eq. (10).

$$
\begin{aligned}
& \phi=\mathrm{F}_{1} \phi_{1}+\left(1-\mathrm{F}_{1}\right) \phi_{2} \\
& \beta_{1}=0.0750, \sigma_{\mathrm{k} 1}=0.5, \sigma_{\omega_{\mathrm{t}} 1}=0.5 \\
& \kappa=0.41, \gamma_{1}=\frac{\beta_{1}}{\beta^{*}}-\sigma_{\omega_{\mathrm{t}} 1} \frac{\kappa^{2}}{\sqrt{\beta^{*}}} \\
& \beta_{2}=0.0828, \sigma_{\mathrm{k} 2}=1.0, \sigma_{\omega_{\mathrm{t}} 2}=0.856 \\
& \kappa=0.41, \gamma_{2}=\frac{\beta_{2}}{\beta^{*}}-\sigma_{\omega_{\mathrm{t}} 2} \frac{\kappa^{2}}{\sqrt{\beta^{*}}}
\end{aligned}
$$

The coefficients in the model are calculated from the blending function $F_{1}$, such that each coefficient $\phi$ is given by Eq. (11). The coefficients of Set $1\left(\phi_{1}\right)$ are given by Eq. (12) and the coefficients of Set $2\left(\phi_{2}\right)$ are given by Eq. (13). And in both Set 1 and Set $2 \beta^{*}$ is 0.09 and $\alpha^{*}$ is 1 .

$$
\begin{aligned}
& \mathrm{F}_{1}=\tanh \left(\arg _{1}^{4}\right) \\
& \arg _{1}=\min \left(\max \left(\frac{\sqrt{\mathrm{k}}}{0.09 \omega_{\mathrm{t}} \mathrm{y}}, \frac{500 v}{\mathrm{y}^{2} \omega_{\mathrm{t}}}\right), \frac{2 \mathrm{k}}{\mathrm{y}^{2} \mathrm{CD}_{\mathrm{k} \omega_{\mathrm{t}}}}\right) \\
& \mathrm{CD}_{\mathrm{k} \omega_{\mathrm{t}}}=\max \left(\frac{1}{\omega_{\mathrm{t}}} \nabla \mathrm{k} \cdot \nabla \omega_{\mathrm{t}}, 10^{-20}\right)
\end{aligned}
$$

The blending function $\mathrm{F}_{1}$ is defined by Eq. (14), with $\arg _{1}$ defined by the Eq. (15), where $\mathrm{y}$ is the distance to the nearest wall, $\mathrm{CD}_{\mathrm{k} \omega_{\mathrm{t}}}$ is related to the cross-diffusion term and $v$ is the kinematic viscosity $\mathrm{CD}_{\mathrm{k} \omega_{\mathrm{t}}}$ is defined by Eq. (16).

$$
\mathrm{F}_{2}=\tanh \left(\arg _{2}^{2}\right)
$$

$$
\arg _{2}=\max \left(\frac{2 \sqrt{\mathrm{k}}}{0.09 \omega_{\mathrm{t}} \mathrm{y}}, \frac{500 v}{\mathrm{y} \omega_{\mathrm{t}}}\right)
$$

The Equation (17) expresses the function $F_{2}$, where the coefficient $a_{1}$ is equal to 0.31 and $\arg _{2}$ is given by the Eq. (18).

$$
\begin{aligned}
& \mu_{\mathrm{t}}=\rho \mathrm{k} \mathrm{T}_{\mathrm{k} \omega_{\mathrm{t}}} \\
& -\rho \overline{\mathrm{u}_{\mathrm{i}}^{\prime} \mathrm{u}_{\mathrm{j}}^{\prime}}=\mu_{\mathrm{t}}\left(\frac{\partial \overline{\mathrm{u}}_{\mathrm{i}}}{\partial \mathrm{x}_{\mathrm{j}}}+\frac{\partial \overline{\mathrm{u}}_{\mathrm{j}}}{\partial \mathrm{x}_{\mathrm{i}}}\right)-\frac{2}{3} \rho \mathrm{k} \delta_{\mathrm{ij}}
\end{aligned}
$$

The relations to find the turbulent viscosity are obtained through the solution of Eqs. (3) and (4). Thus, the turbulent viscosity $\mu$ can be expressed by Eq. (19) and related to the Reynolds tensor by Eq. (20), solving the closure problem. In the Equation (20), $\delta_{\mathrm{ij}}$ is the Kronecker delta operator.

\section{Wall Treatment}

A hybrid treatment solution on the wall was done in this research work. Using this treatment, the laminar sub layer in the region of fine mesh, for dimensionless wall distance, $\mathrm{y}^{+}$, less than three, is calculated and in other areas it use a logarithmic profile for the boundary layer.

$$
\begin{aligned}
& \mathrm{y}^{+}=\frac{\mathrm{yu}^{*} \mu}{\rho} \\
& \mathrm{g}=\exp \left(\frac{\mathrm{Re}_{\mathrm{y}}}{11}\right)=\exp \left(\frac{\sqrt{\mathrm{ky} / \mathrm{v}}}{11}\right) \\
& \mathrm{u}^{*}=\sqrt{\frac{\mathrm{g} v \mathrm{u}}{\mathrm{y}}+(1-\mathrm{g}) \beta^{* 1 / 2} \mathrm{k}} \\
& \mathrm{G}_{\mathrm{k}}=\mathrm{g} \mu_{\mathrm{t}} \mathrm{S}^{2}+\frac{(1-\mathrm{g})}{\mu}\left(\frac{\rho \mathrm{u}^{*} \mathrm{u}}{\mathrm{u}^{+}}\right)^{2} \frac{\partial \mathrm{u}^{+}}{\partial \mathrm{y}^{+}} \mathrm{k} \\
& \omega_{\mathrm{t}}=\mathrm{g} \frac{6 v}{\beta \mathrm{y}^{2}}+(1+\mathrm{g}) \frac{\mathrm{u}^{*}}{\sqrt{\beta^{*} \kappa \mathrm{y}}}
\end{aligned}
$$

$\mathrm{y}^{+}$is evaluated by the Eq. (21), where $\mathrm{u}^{*}$ is a reference velocity. For the hybrid wall treatment, or 
all $\mathrm{y}^{+}$wall treatment, that is used in this work, a hybrid function $\mathrm{g}$ is defined in terms of Reynolds number based on distance from the wall, Rey, according to Eq. (22). The reference velocity $\mathrm{u}^{*}$, production in the wall cell $\mathrm{G}_{\mathrm{k}}$ and specific dissipation in the wall cell $\omega_{t}$, are given by Eqs. (23), (24) and (25), respectively, where $\mathrm{u}^{+}$is wall-parallel velocity (u) non-dimensionalized with $\mathrm{u}^{*}$.

\section{Boundary, Region and Initial Conditions for the Turbulence}

The boundary condition for $\mathrm{k}$ on the walls is $\partial \mathrm{k} /\left.\partial \mathrm{n}\right|_{\mathrm{w}}=0$, with $\mathrm{n}$ indicating the normal direction, and for $\omega t$ is specified in the wall cells according to the appropriate method in the wall treatment.

$$
\begin{aligned}
& \mathrm{k} \approx \frac{3}{2}(\mathrm{I} v)^{2} \\
& \omega_{\mathrm{t}} \approx \frac{\sqrt{\mathrm{k}}}{\mathrm{L} \beta^{+1 / 4}}
\end{aligned}
$$

The Equations (26) and (27) are used as initial conditions for $\mathrm{k}$ and $\omega_{\mathrm{t}}$, respectively, where $\mathrm{I}$ is turbulence intensity and $\mathrm{L}$ is length scale. In this research work, it was assumed the turbulence intensity equal to $1 \%$ and the length scale of $0.01 \mathrm{~m}$ at the calculation domain. These values are used in the rest of the calculation domain as an initial condition. $\beta^{+}$is a coefficient of the model.

\section{Details of the Numerical Method}

All these equations are discretized through the Finite Volume Method, which creates a system of linear algebraic equations that is solved iteratively using the Gauss-Seidel Method. The temporal terms of the equations are discretized using a fully implicit temporal scheme. The discretization of the advective terms of the conservation equations, responsible for the transport of scalar variables through the motion of fluid particles in the flow, is achieved by the interpolation function Second Order Upwind, more accurate than first order schemes. The method SIMPLE (Semi Implicit Linked Equations) is used to make the coupling between pressure and velocity calculations, ensuring good stability for the solution (Maliska, 1995; Star-CCM+ , 2008; Akwa, 2010).

\section{Calculation of Moment and Power Coefficients}

$$
\begin{aligned}
& \mathrm{T}=\sum_{\mathrm{f}}\left[\boldsymbol{k}_{\boldsymbol{f}} \times\left(\boldsymbol{F}_{\boldsymbol{f}}^{\text {pressure }}+\boldsymbol{F}_{\boldsymbol{f}}^{\text {shear }}\right) \cdot \boldsymbol{d}\right]= \\
& \sum_{\mathrm{f}}\left\{\boldsymbol{k}_{\boldsymbol{f}} \times\left[\left(\mathrm{p}_{\mathrm{f}}-\mathrm{p}_{\mathrm{ref}}\right) \boldsymbol{d}_{\boldsymbol{f}}+\left(-\boldsymbol{\tau}_{\boldsymbol{f}} \cdot \boldsymbol{d}_{\boldsymbol{f}}\right)\right] \cdot \boldsymbol{d}\right\}
\end{aligned}
$$

Holding the solution of conservation equations and turbulence model, one can obtain the rotor moment, $\mathrm{T}$, by integrating the forces resulting from the tensions that act on the buckets. The rotor moment is calculated by Eq. (28), where $\boldsymbol{F}_{\boldsymbol{f}}^{\text {pressure }}$ and $F_{f}^{\text {shear }}$ are the pressure and shear force vectors and $\mathrm{d}$ is a vector defining the axis through point $\mathrm{x}_{0}$ about which the moment is taken and $\mathrm{k}_{\mathrm{f}}$ is the position of face $f$ relative to $x_{0}$. The pressure force vector on surface face $f$ is computed from: $p_{f}$ that is the face pressure, $d_{f}$ that is the face area vector, and $p_{\text {ref }}$ that is the reference pressure. As defined, this is the force that the fluid exerts on the surface. The shear force on surface face $\mathrm{f}$ is computed by the stress tensor at face $f$, $\tau_{f}$, and $d_{f}$. This is the shear force exerted on the surface by the fluid (Star-CCM $\left.{ }^{+}, 2008\right)$.

With the moment value obtained by Eq. (28) and the value of the rotation rate, $\omega$, which is imposed as a boundary condition in each simulation, the rotor power, $\mathrm{P}$, can be calculated because $\mathrm{P}=\mathrm{T} \omega$. Dividing the rotor power by the power available in the air flow that focuses on the projected area of the rotor, $A_{r}$, one can obtain the relationship between the power coefficient, $\mathrm{C}_{\mathrm{P}}$, moment coefficient, $\mathrm{C}_{\mathrm{T}}$, and the tip speed ratio of the rotor, $\lambda$.

$$
\begin{gathered}
\mathrm{C}_{\mathrm{P}}=\frac{\mathrm{P}}{\mathrm{P}_{\text {available }}}=\frac{\mathrm{T} \omega}{1 / 2 \rho \mathrm{A}_{\mathrm{r}} \mathrm{V}_{\mathrm{o}}^{3}}= \\
\frac{\mathrm{T}}{1 / 2 \rho \mathrm{A}_{\mathrm{r}} \mathrm{V}_{\mathrm{o}}^{2} \mathrm{r}} \frac{\mathrm{r} \omega}{\mathrm{V}_{\mathrm{o}}}=\mathrm{C}_{\mathrm{T}} \lambda
\end{gathered}
$$

The relationship between the aerodynamic coefficients, which is used to calculate the dimensionless aerodynamics coefficients of the rotor, is represented by the Eq. (29), where $r$ is the radius of the Savonius rotor. The results of this research work are expressed by the averaged moment and power coefficients as functions of tip speed ratio of the rotor for a Reynolds number equal to 433,500 (Akwa, 2010).

As the methodology adopted by Akwa (2010), the value of moment coefficient for the static rotor without stator was obtained for computational simulations with use of several cells quantities in the domain calculation to verify the adequacy of the spatial discretization. To check this, the rotor was positioned at zero degrees $\left(\theta=0^{\circ}\right)$ in the simulations. It appears that the solution does not vary significantly with spatial discretization made to take cells mediumsized of $0.0450 \mathrm{~m}$ and cells minimum dimensions on the order of $0.0001 \mathrm{~m}$. The solution obtained for this condition differs by only $0.2 \%$ of the solution obtained with the use of an average size of $0.0230 \mathrm{~m}$ and minimum of about $6 \times 10^{-5} \mathrm{~m}$ for the cells of the calculation domain. To minimize the dependence of the solution regarding the degree of temporal discretization, the angular step given each time step by the rotor in the transient simulations was lowered 
until it is not shown significant dependence of the averaged moment coefficient of the rotor on this parameter. The same methodology was performed for the other computer simulations using different geometries of the Savonius wind turbines.

\section{RESULTS AND DISCUSSION}

The simulations performed for the operation of the Savonius wind turbine containing stators considered in this research work result in behaviors for the averaged moment and power coefficients displayed in Fig. 4 and 5. From the figures, it appears that the results are representative of the analyzed phenomenon because the simulated values for free Savonius rotor are in agreement with those measured by other authors in the recent times as D'Alessandro et al. (2010) for similar rotor and flow conditions. Analyzing these figures, one can see that only the turbine containing the cylindrical stator with three openings and the turbine with the use of four deflector blades get better performance than the free Savonius rotor, but only for some ranges of tip speed ratio. In Figure 6, the complex flow on the turbine containing four deflector blades can be observed.

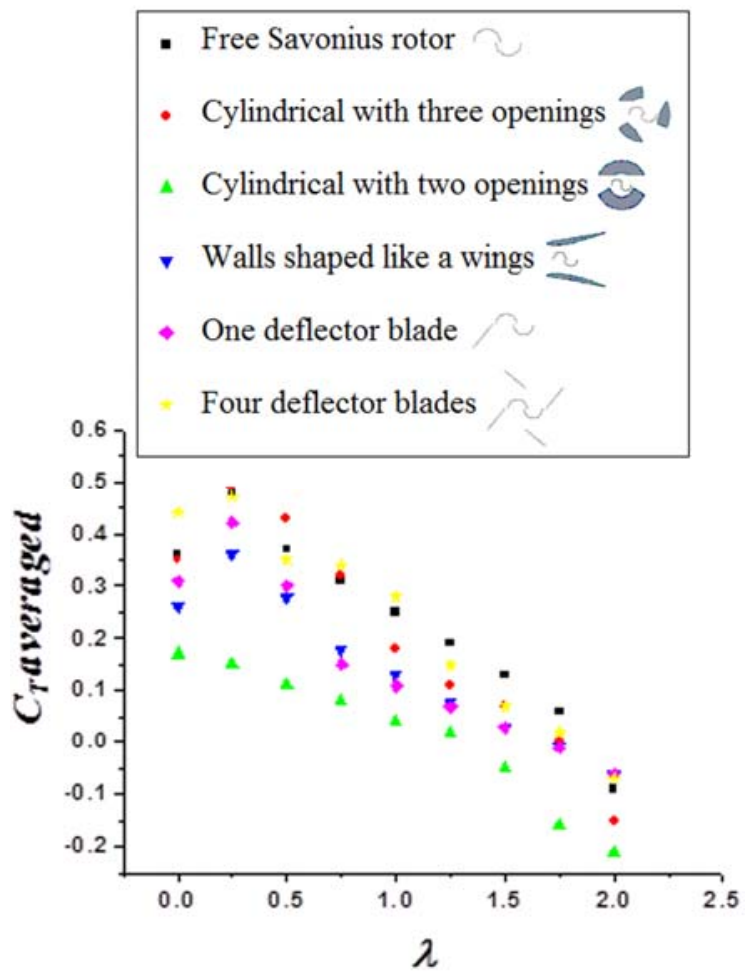

Figure 4. Averaged moment coefficient versus tip speed ratio.

The turbines with the use of other types of stators have not obtained performance improvements in relation to the operation of the free Savonius rotor. The tendency to all wind turbines with stators submit power coefficients with approximate values exists to much low tip speed ratios. The rotor with the use of one deflector blade has a power coefficient greater than a free Savonius rotor power coefficient to high tip speed ratios. However, both for high and low tip speed ratios, the improved performance is not satisfactory, due to turbine efficiency is low, which is not attractive for power generation.

The turbine containing cylindrical stator with three openings of similar geometry to that studied by Sabzevari (1978) provides operating averaged moment and power coefficients higher than those provided by the free Savonius rotor. This superiority is only to the tip speed ratios from 0.25 to 0.75 . For other tip speed ratios there is not improved using this type of stator. The increase that occurs in the performance of the turbine with the use of such stator is very small and does not occur in the range of the highest power coefficients obtained by the free Savonius rotor. The performance increase that is obtained in this study is also lower than the increase obtained by Sabzevari (1978). This difference between the results can be clearly explained by the way Sabzevari obtained values for $V_{0}$. Sabzevari assigned the value of the averaged velocity at the stator inlet as the undisturbed velocity of the air flow. The velocity at the stator inlet has a value much lower than the undisturbed velocity value, providing values much higher than the actual values for the power coefficients.

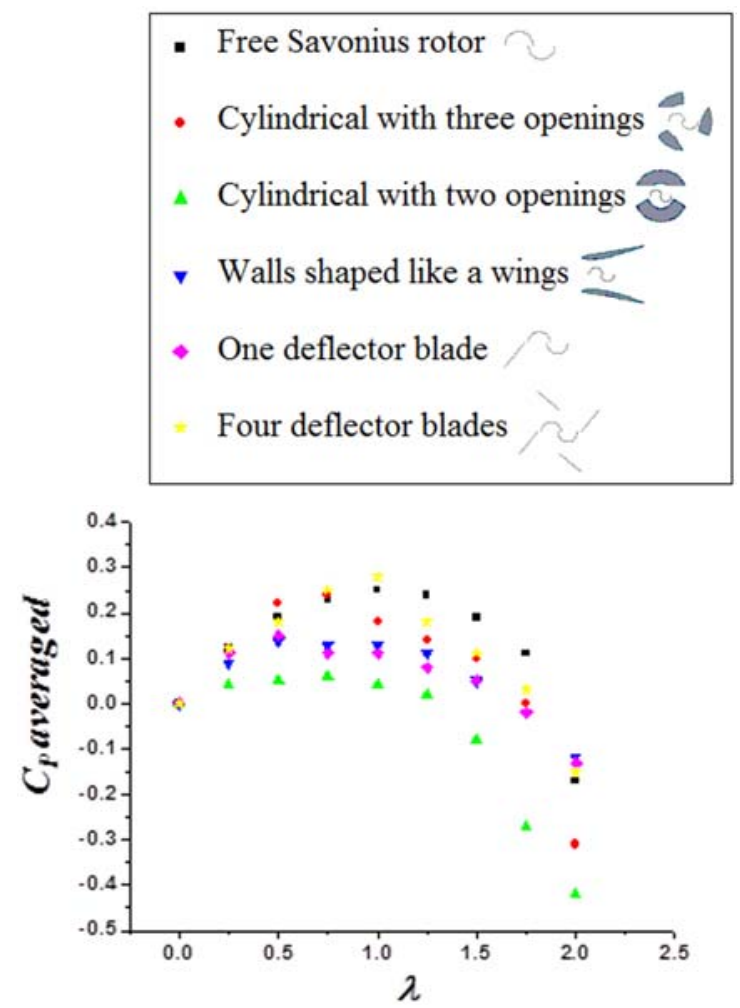

Figure 5. Averaged power coefficient versus tip speed ratio.

Improvement in the averaged moment and power coefficients is not achieved in the use of a Savonius turbine containing cylindrical stator with 
two openings. The dimensions of the turbine stator provide an intense blockage on the air flow. The swirls that arise downstream of the stator in the rotor operation could affect the passage of air flow through the interior of the stator, reducing the mass flow and, consequently, the rotor power. Nor is obtained rotor performance improvement using a Savonius turbine containing a stator with walls shaped like wings. The gain in performance with the use of such stators, as discussed by Hansen (2008), is not obtained in this research work. The walls shaped like a wings do not provide a significant increase in the velocity of air flow through the operation plane of the rotor. Moreover, the presence of these walls causes an obstruction in air flow, decreasing the available energy in the operation of the rotor.

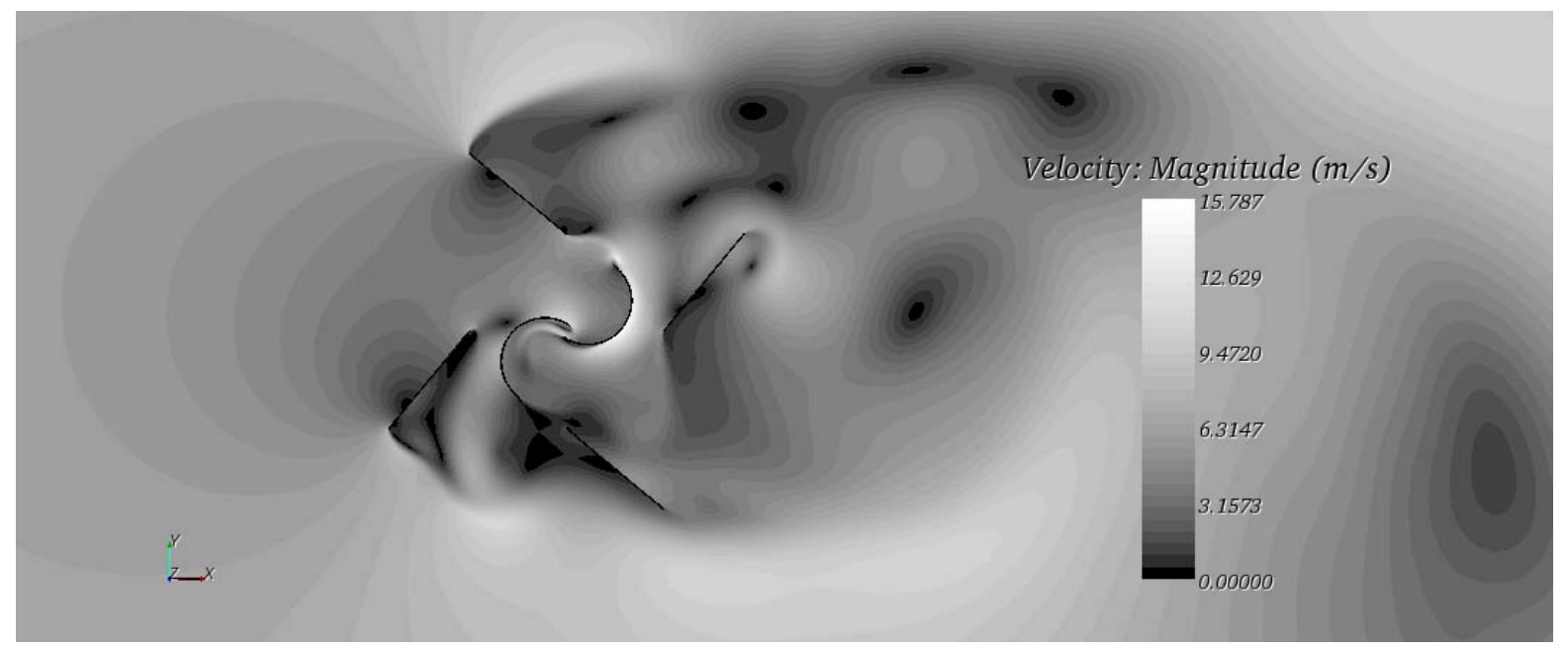

Figure 6. Isovelocity lines for flow on Savonius turbine with four deflector blades at $\lambda=1, \theta=300^{\circ}$.

It appears that the use of a greater number of deflector blades provides higher averaged moment and power coefficients. This is caused by the better direction of air flow on the concave side of the advancing bucket with the use of a greater number of deflectors. The air mass diffusion downstream of the stator is also favored with the use of higher amount of deflector blades. The value obtained for the maximum averaged power coefficient with the use of a turbine containing stator with four deflector blades is equivalent to 0.28 , noting that the corresponding value obtained for the operation without stator is 0.25 . This increase in rotor performance, however, cannot justify an increase in complexity and cost of the Savonius wind turbine. Further investigation about the operating conditions and geometric configuration of this type of stator must be conducted in future studies.

\section{CONCLUSIONS}

This study is developed in order to verify numerically the influence of different stators settings in the performance of Savonius wind turbines, with the aim of optimizing the geometry of the wind device. This research work gets physically consistent results and has good agreement with other studies, for the condition with the rotor without stator. Thus, one can conclude that the used parameters are suitable for all analysis performed in this research work. In the best conditions obtained, the use of four deflector blades at tip speed ratio equal to 1.00 provided improvement percentage in performance equal to $12 \%$ compared to the performance of the rotor operating without stator. This is caused by the better direction of air flow on the concave side of the advancing rotor bucket with the use this type of stator. The device can be used more successfully in applications with wind coming from several directions with greater number of deflector blades. However, this small increase in rotor performance cannot justify an increase in complexity and cost of the Savonius wind turbine.

In future researches, new settings for wind rotors can be analyzed so it can get an optimized model. It is interesting also perform $3 \mathrm{D}$ simulations of turbine to the $3 \mathrm{D}$ parameters that affect performance, such as aspect ratio, can be analyzed. Moreover, effects of the terrain, turbulence intensity and shaft can be included in the simulations to provide more realistic conditions. The operation of the device can be evaluated for other flow conditions and using different stator geometries. This study confirms that the Finite Volume Method can be applied successfully to the study of Savonius turbines. The explained methodology is a promising tool, since it helps to steer future improvements of this rotor, optimizing their performance.

\section{ACKNOWLEDGEMENTS}

The authors thank the financial support from CNPq through a scholarship grant to J.V. Akwa. 


\section{REFERENCES}

Akwa, J. V., Wenzel, G. M., Zancanaro, F. V. Jr, Vielmo, H. A., Petry, A. P., 2009, Analysis and Computational Simulations of the Flow Through Stators Designed for Power Augmentation in Savonius Wind Turbines, Proceedings of the COBEM 2009, 20th International Congress of Mechanical Engineering, Gramado, Brazil.

Akwa, J. V., 2010, Análise Aerodinâmica de Turbinas Eólicas Savonius Empregando Dinâmica dos Fluidos Computacional, MSc Dissertation, Federal University of Rio Grande do Sul, Porto Alegre, RS, Brazil. (in Portuguese)

D’Alessandro, V., Montelpare, S., Ricci, R., Secchiaroli, A., 2010, Unsteady Aerodynamics of a Savonius wind rotor: a new computational approach for the simulation of energy performance, Energy, Vol. 35, pp. 3349-3363.

Eldridge, F. R., 1980, Wind Machines, 2nd Edition, Van Nostrand Reinhold.

Fernando, M. S. U. K., Modi, V. J., 1989, A Numerical Analysis of the Unsteady Flow Past a Savonius Wind Turbine, Journal of Wind Engineering and Industrial Aerodynamics, Vol. 32, pp. 303-327.

Hansen, M. O. L., 2008, Aerodynamics of Wind Turbines, Earthscan.

Maliska, C. R., 1995, Transferência de Calor e Mecânica dos Fluidos Computacional, LTC.

Menter, F. R., Kuntz, M., 2002, Adaptation of Eddy Viscosity Turbulence Models to Unsteady Separated Flows Behind Vehicles, In: The Aerodynamics of Heavy Vehicles: Trucks, Buses and Trains, Springer.

Patankar, S. V., 1980, Numerical Heat Transfer and Fluid Flow, McGraw-Hill.

Sabzevari, A., 1978, Power Augmentation in a Ducted Savonius Rotor, Proceedings of the 2nd International Symposium on Wind Energy Systems, Amsterdam, Netherlands, Vol. 1, pp. 25-34.

Savonius, S. J., 1930, Wind Rotor - Patent 1,766,765, United States Patent Office.

Star-CCM ${ }^{+}, 2008$, Methodology, CD-adapco.

Vance, W., 1973, Vertical Axis Wind Rotors Status and Potential, Proceedings of the Conference on Wind Energy Conversion Systems, Washington, USA, Vol. 1, pp. 96-102.

Wilcox, D.C., 1998, Turbulence Modeling for CFD, DCW Industries.

Received: July 30, 2011

Revised: August 30, 2011

Accepted: September 30, 2011 